\title{
O autor
}

\section{João Miguel Moreira Auto IEL, UNICAMP}

\section{Abstract}

The aim of this article is to discuss some important questions on the meaning of the concept of "author". First, it explains how Roland Barthes criticizes such a notion by stressing the reader's role in the comprehension of a text's meaning. Then, Foucault is mentioned: he notes the important role the reader plays for the unity of the text's sense, but he is also aware of the possibility of a readable "author function"; the reader himself is the one who makes us realize the actual existence of authorship. Also discussed is Possenti's hypothesis that it is possible to look for traces of autborship, for example, in a simple text. Finally the following definition of the concept is proposed: authorship is a kind of linguistic and discursive attitude, an act of inscription by which the agent takes one's stand and articulates foregoing discourses and a later reception, according to personal tactics and specific style. 


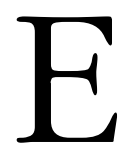

m seu célebre livro O rumor da lingua, Roland Barthes incluiu um polêmico texto, A morte do autor (1988), que servirá, juntamente com os textos O que é um autor? ${ }^{2}$ e $A$ escrita de $s i{ }^{3}$ de Michel Foucault (2000), e os textos Enunciação, autoria e estilo (1992) e Indícios de autoria (2002), de Sírio Possenti, para conduzir nossas discussões neste trabalho. Antes de assassinar o autor, no entanto, Barthes tomou o breve cuidado de fazê-lo nascer em duas linhas quando afirmou: "o autor é uma personagem moderna, produzida sem dúvida por nossa sociedade na medida em que, ao sair da Idade Média, com o empirismo inglês, o racionalismo francês e a fé pessoal da Reforma, ela descobriu o prestígio do indivíduo ou, como se diz mais nobremente, da 'pessoa humana" (1988, p. 66). Para ele, portanto, o autor é uma construção discursiva e histórica, e, em certo sentido, hoje, ultrapassada. Em seu lugar coloca o escritor, vinculado à escrita, não à criação, o qual menos "se expressa", "representa", ou produz mimese, do que faz "performance", ou "inscrição" num campo lingüístico dinâmico (e, portanto, indefinido) e social (e, portanto, disperso) (1988, p. 68). Além disso, Barthes faz notar que a unidade de sentido do texto não está na sua origem autoral, mas no seu destinatário, o leitor, esse apenas "alguém" vazio de pessoa, história, biografia e psicologia (1988, p. 70). Por isso assevera: “o nascimento do leitor deve pagar-se com a morte do Autor" (1988, p. 70).

Já Foucault, um historiador de discursos, associou a autoria à problemática da diferença entre autenticidade e atribuição, ao estudo da relação autor e obra e, enfim, à produção de biografias de preferência a narrativas heróicas (2000, p. 34). Certamente, também Foucault associa a autoria à modernidade, embora faça notar que, no campo das ciências, a legitimidade autoral do saber foi substituída nos séculos XVII e XVIII pela legitimidade teórica e metodológica: se é verdadeiro, não 
é o selo do autor que o autoriza, mas, simplesmente, sua cientificidade (2000, p. 49). É que a autoria veio a encontrar seu reinado em outro campo, qual seja, o das "humanidades" e, para Foucault, em particular, o campo dos discursos literários (2000, p. 49). Ora, para ele, ainda, só no fim do século XVIII e no início do XIX (portanto a partir do Romantismo) é que a enunciação, que era até então um apenas ato, tornou-se uma propriedade, poderíamos dizer uma "extensão do autor", espécie de digital gráfica que o ultrapassa espacio-temporalmente e, supostamente, o difunde. Nesse sentido, a transgressividade do discurso (transgressividade essa que acharia seu extremo na literatura romântica) é a condição para o estabelecimento de um vínculo político que a autoria supõe entre o escritor e a obra (2000, p. 47-48).

A modernidade não é, no entanto, eleita por ele como espaço único da autoria; pelo contrário, ele acredita que "para 'reencontrar' o autor na obra, a crítica moderna utiliza esquemas muito próximos da exegese cristã quando esta queria provar o valor de um texto através da santidade do autor" (2000, p. 51). Em seguida, Foucault falará de S. Jerônimo. Para que se compreenda seu raciocínio, será preciso, entretanto, fazer compreender sua visão da autoria, ou do que chama "função autor". Assim como Barthes, Foucault parece consciente de que a escrita não pode ser compreendida separada da leitura. Para ele, "o nome próprio e o nome de autor encontram-se situados entre os pólos da descrição e da designação” (2000, p. 42), sendo que compreender o autor exclusivamente sob o ponto de vista da "designação", como índice pessoal e histórico, corpo físico dotado de estatuto político e, nesse sentido, capacitado para a ação - seria achatá-lo. O autor deve ser compreendido em face da obra, pois que "o nome de autor faz com que os textos se relacionem entre si" (delimitando a obra e modificando seu sentido), servindo assim "para caracterizar um certo modo de ser do discurso" (2000, p. 45). Nesse sentido, nem bem chega a ser uma pessoa, nem bem é discurso: transita neste hiato e não se resolve, sendo, portanto, na sua essência, um conceito problemático. ${ }^{4}$ Só tendo isso em conta é que se pode compreender a afirmação foucaultiana segundo a qual "todos os 
discursos que são providos da função autor comportam esta pluralidade de 'eus' " (2000, p.55). ${ }^{5}$

Aprofundemo-nos só mais um pouco: se disséssemos (como parece tentador) que o autor é a pessoa física e histórica que tem por característica ser a causa e a origem de uma obra (fazendo assim desta uma sua derivação), não chegaríamos satisfatoriamente a uma solução do problema. A princípio, é claro, parece fácil estabelecer essa clivagem, colocando um à frente do outro e delimitando separadamente os seus lugares através de uma relação de anterioridade causal. Isso, no entanto, seria excluir o nosso papel, como intérpretes, no percurso histórico de realização da obra enquanto tal - perigosa mistificação da linguagem. E aí é que nos diz Foucault: "uma carta privada pode bem ter um signatário, mas não tem um autor; um contrato pode bem ter um fiador, mas não um autor" (2000, p. 46) - ou nos indaga: "como definir uma obra entre os milhões de vestígios deixados por alguém depois da morte?" (2000, p. 38). Portanto, se dependemos da autoria para compreender os limites da obra, a relação inversa, de dependência da obra para o estabelecimento de uma autoria, não deixa de ser verdadeira: não se trata aqui de uma construção conceptual linear, mas dialética. Voltaremos a falar mais adiante da unidade autor/obra em Foucault e suas conseqüências teóricas. Por enquanto, basta que nos conscientizemos de que essa unidade existe para ele, e de que isso, apenas, é motivo para que ele a trate como tal.

Voltando agora a S. Jerônimo, podemos compreender melhor o movimento lógico que Foucault estabelece a seu respeito. Quando discutia a obra, esse santo traçava, indiretamente, por meio de uma projeção lógica involuntária, os contornos da autoria. Procurou diferenciar a obra espúria da legítima através de quatro critérios de exclusão, quais sejam: 1) excluir da obra os livros piores; 2) excluir os textos que contradizem a doutrina da obra; 3) excluir as obras que têm o vocabulário, os usos de linguagem ou o estilo de tipo diverso do que se encontra no resto da obra; 4) excluir o que contiver referências póstumas. Os quatro critérios apontados dizem respeito a características especificamente discursivas do texto, sendo que só o último deles 
se refere a fatores claramente históricos. Foucault, no entanto, os lê à luz de sua teoria e nos diz: o autor é: 1) "um nível constante de valor"; 2) "uma coerência conceptual ou teórica"; 3) "uma unidade estilística"; 4) "um momento histórico definido" (2000, p. 52). Retirando-se, por exclusão, como um escultor diante da estátua, o excesso que se lhe pega à face, o crítico determina a exata forma da obra, ao mesmo tempo em que logo ao lado se projeta, meio por si mesma, como uma sombra insuspeita, a silhueta tremeluzente do autor.

Se compreendermos, ainda, que, para esse pensador "a noção de autor constitui o momento forte da individualização na história das idéias" (2000, p. 33), ficará fácil compreender a importância da literatura cristã e pré-cristã (em particular a estóica) como elemento mais remoto na gênese desta categoria, a saber, a de autoria (lembremos aqui de Sto. Agostinho e do papel do livre-arbítrio na relação do homem com o pecado). Ora, para não nos determos nas "Confissões" agostinianas (o que ultrapassaria em muito o fôlego do trabalho), cujo título já fala, de si, alguma coisa a respeito do papel da alteridade (e da culpa) no processo de individuação do sujeito em busca de uma identidade para si, gostaria de recuar um pouco mais no tempo, apoiando-me para isso em A escrita de si (2000, p. 129-160), também de Foucault. De acordo com ele, os pitagóricos, os socráticos e os cínicos já tinham, desde antes, o hábito da ascese, isto é, do adestramento de si ("abstinências, memorizações, exames de consciência, meditações, silêncio e escuta de outro") (2000, p. 132). No entanto, o que é novidade a partir dos primeiros séculos de nossa era é a inclusão da prática da escrita nesses processos de autovigilância, o que confere à escrita uma função que Plutarco teria chamado etopoiética, ou, nos termos de Foucault, ela "é um operador da transformação da verdade em ethos" (2000, p.134).

Esse tipo de escrita pode ser encontrado na correspondência de homens como Sêneca, Plínio ou Marco Aurélio, ou nos hipomnemata. Estes últimos funcionavam como espécie de agendas ou cadernos de notas (não exatamente diários, pois não eram simples narrativas) que serviam como guias de conduta para a vida e memória material 
para coisas "lidas, ouvidas ou pensadas" (2000, p. 135). Podiam servir como matéria-prima para a produção de tratados que versavam sobre como lutar com defeitos ("como a cólera, a inveja, a tagarelice, a bajulação") (2000, p. 135) ou o que fazer em situações difíceis ("um luto, um exílio, a ruína, a desgraça”) (2000, p. 135). É notável, sobretudo, como essas anotações, recolhidas de fontes diversas, muitas vezes intencionalmente descontextualizadas e mesmo modificadas em seu sentido, tornavam-se, pelo exercício metódico de leitura, com vistas à "subjetivação do discurso" (2000, p. 137), o instrumento de constituição de uma identidade ética una para um "eu" vivo, atuante e coerente, ou, como disse Foucault em passagem de não pequena importância, a escrita "transforma-se no próprio escritor, num princípio de ação racional" (2000, p. 143).

A respeito disso, o próprio Foucault comenta: "no interior de uma cultura muito fortemente marcada pela tradicionalidade, pelo valor reconhecido ao já dito, pela recorrência do discurso, pela prática 'citacional' com a chancela da antiguidade e da autoridade, desenvolviase uma ética muito explicitamente orientada pelo cuidado de si para objetivos definidos como: retirar-se para o interior de si próprio, alcançar-se a si próprio, viver consigo próprio, bastar-se a si próprio, tirar proveito e desfrutar de si próprio" (2000, p. 137-138). Nesse sentido, a escrita funcionava como "maneira de recolher a leitura feita e de nos recolhermos sobre ela" (2000, p. 139) e se opunha à stultitia, espécie de agitação do espírito, volubilidade das inclinações ou inconstância de opiniões que, segundo os sábios do período, nos distancia da fixidez da verdade e do conforto da paz.

Aqui, chama atenção esta passagem da carta 84 de Sêneca, referida por Foucault: "Digiramos a matéria: de outro modo, ela passará à nossa memória, mas não à nossa inteligência" (FOUCAULT, 2000, p. 143); e no mesmo local, como se Sêneca houvesse ali querido arremedar nossa época, encontra-se, ainda, esta passagem, que bem nos soa estranhamente bakhtiniana: "Nenhuma voz individual se pode aí distinguir; só o conjunto se impõe ao ouvido... Assim quero que seja com a nossa alma, que ela faça boa provisão de conhecimentos, de 
preceitos, de exemplos tirados de mais do que uma época, mas convergentes numa unidade" (FOUCAULT, 2000, p. 144-145). Não se pretende aqui transportar para a antiguidade as discussões do século XX acerca de conceitos lingüísticos como o de "polifonia"; em vez disso pretendemos apenas rastrear, indo tão longe quanto possível, a gênese do discurso autoral em sua relação com uma individualidade dotada de caráter pessoal e de uma consciência discursiva, digamos, "interior" (onde interior significa apenas não necessariamente manifesta), sendo que, para isso, devemos ter em linha de conta que o indivíduo só se realiza em sua identidade pessoal a partir de um posicionamento no âmbito de um espaço coletivo, e com base em habilidades lingüísticas adquiridas no decorrer de práticas igualmente coletivas.

Se os hipomnemata despertam interesse por tornarem evidente o preponderante papel da alteridade lá nas origens mais remotas da constituição de uma identidade de si mesmo no âmbito do registro escrito - que dizer então das correspondências de alguns escritores da época, as quais, segundo Foucault, muito se aproximam dos bipomnemata (2000, p. 145), e nas quais Sêneca "continua a exercitarse a si próprio" (2000, p. 146), mas que se distinguem daqueles textos porque, sendo cartas, são "uma certa maneira de cada um se manifestar a si próprio e aos outros" (2000, p. 149), ou, de modo mais sucinto, um "face-a-face" (2000, p. 150) em que há reciprocidade de conselho e exame (2000, p. 151). Assim, à subjetivação do bom discurso, e verdadeiro, tal como ocorria nos hipomnemata, as correspondências que Foucault analisa acrescentam um ingrediente de "objetivação da alma" (2000, p. 151), que desse modo tornavase manifesta em forma de texto, já para quem os redigia então, e, depois, historicamente, para quem os porventura leia.

Podemos concluir que a voz da autoria vem de uma espécie de poço profundo, porém o que está no fundo do poço não é uma substância subjetiva, pessoal e concreta, mas uma forma pulsante que se materializa e se dilui, à superfície ondulante da linguagem: ou, melhor, não há fundo, mas apenas um labirinto de espelhos móveis em que se reflete uma enorme variedade de significados, ou uma 
floresta entrelaçada de sentidos em flor. Um texto não será nunca linear nem unívoco, mas comporta múltiplas dimensões, escrituras variegadas, diversos sentidos; enfim, constitui-se como tecido de citações. Assim, o fio da meada do sentido "original" se emaranha e se perde, pois a própria escrita não é senão este amontoado de ecos que se embatem, se negam, se misturam e se iluminam mutuamente, multiplicando-se, fragmentando-se, recompondo-se e transformando-se perpetuamente. Para Barthes, dar ao texto um autor seria fechar-lhe a escritura. Por isso - argumenta - a crítica escolástica ama o autor. Ele representa o ponto final de seu ávido percurso (BARTHES, 1988, p. 68-69).

Se, contudo, Barthes chegou a afirmar, como dizíamos logo no início desse texto, que "o nascimento do leitor deve pagar-se com a morte do Autor" (1988, p. 70), creio, todavia, que é possível achar um caminho para sua ressurreição se (seguindo nisso as pegadas de Foucault) refletirmos que o enunciado de Barthes não pode fazer sentido diante da perspectiva de que a autoria, enquanto função discursiva, pode, ela mesma, ser objeto de leitura. Portanto, o reconhecimento da relevância do leitor no processo lingüístico de construção de sentidos não exclui, do ponto de vista de uma lingüística discursiva, a possibilidade da existência de um conceito de autoria, conceito esse pertinente e fecundo. Trata-se, aqui, não de suprimir a pessoa física do autor (o que seria impossível), mas de jogá-la para um segundo plano e colocar em seu lugar o autor enquanto manifestação lingüística, como discursividade.

Poderíamos, então, retornar à pergunta foucaultiana referida há pouco: "como definir uma obra entre os milhões de vestígios deixados por alguém após a morte?". ${ }^{6}$ Já notamos que a simples apresentação dessa pergunta torna evidente, pela problemática que introduz, que "autor" e "obra" são duas unidades discursivas que se desafiam e determinam mutuamente, como duas cobras que se pegam pelo rabo e não se sabe, dentre elas, qual contém, qual está contida: pois o autor não reúne em si tudo o que é preciso saber para estabelecer os limites da obra; pelo contrário, a resposta a essa pergunta é a resposta de como 
a obra se forma "por si mesma" (ou melhor, por um possível leitor). Ora, mas justamente a resposta a essa pergunta, ela mesma não foi então dada - e é isso, portanto, que é preciso ainda ser feito.

Como bem observou Possenti em seu Indicios de autoria, a perspectiva adotada por Foucault parece estreitar ainda bastante o alcance do conceito "autor", uma vez que o prende à noção de "obra", como dizíamos há pouco, ou à de "discursividade", sendo o autor, nesse segundo caso, alguém que estabelece "a possibilidade e a regra de produção de outros textos” (POSSENTI, 2002, p. 107-108). Em ambos os casos, porém, o enunciador ordinário, o homem comum, está excluído da autoria. Naturalmente, o famoso filósofo mostrou-se sensível ao que lhe é familiar em razão de seu próprio método, como refinado leitor da história, verdadeiro historiador de discursos que é (estando, pois, mais afeito ao universo privilegiado do texto célebre, e da "obra", em razão, segundo penso, tanto da densidade de sentidos que só esse tipo de documento apresenta como de sua pertinência e centralidade, sendo tanto efeito como causa de uma grande quantidade de signos históricos). Nesse mesmo texto, contudo, e no Enunciação, autoria e estilo (POSSENTI, 1992), Possenti propõe uma sistematização teórica do que chama, justamente, "indícios de autoria". Nesse sentido, a autoria passaria a ser encarada como algo que deixa suas marcas no texto e, portanto, como algo que pode ser brevemente lido, algo independente de um processo histórico mais amplo de consagração do tipo da "obra" ou da "discursividade". Essa perspectiva deixa de lado a psicologia do "gênio" criador, tal como era proposta pela estética romântica, mas não a singularidade do agente autoral.

Procurarei reproduzir aqui, ainda que muito a meu modo, as bases dessa nova teoria autoral, de não pequena pertinência, tal como a entendi. Proponho, por minha conta, uma sistematização baseada em três tipos diferentes de atitudes autorais. A autoria se apoiaria assim num tripé comportamental-discursivo, de modo a podermos dizer: é autor todo aquele que, ao escrever, não negligencia o que poderíamos chamar de a tríplice atitude autoral, a ver: 1) darvoz ao 
outro(POSSENTI, 2002, p. 112-114), isto é, procurar indicar para o leitor, na medida do possível, de onde vem o que está sendo veiculado, ou senão, pelo menos, mostrar-se consciente de que o que se diz vem, em geral, de algum lugar; 2) tomar distanciamento do texto, como dizia Possenti, através de uma atividade "metaenunciativa" (2002, p. 114-116), ou, como prefiro dizer, dar ouvido ao outro, isso é, mostrarse consciente de para onde vai o texto. Isso inclui não dizer obviedades, por um lado, mas também, inversamente, precaver-se contra possíveis críticas ou más interpretações, através de esclarecimentos, de acordo com as possibilidades e os limites interpretativos de um leitor suposto. O autor poderá, ainda, jogar com as expectativas, as opiniões, ou enfim, as inclinações desse leitor, tal como Aristóteles, por exemplo, recomendou na Retórica; 3) manifestar uma singularidade estilística, portanto, em certo sentido, uma pessoalidade, mas não psicológica, ou romântica, e sim, discursiva.

Possenti propõe uma noção de estilo não romantizada e baseada não num princípio de "desvio" (de um suposto padrão que, afinal, não é possível determinar), mas num de "escolha"; todavia ele esclarece - essa escolha não significa um ato sempre intencional de um autor consciente, e, muito menos, o absoluto domínio das múltiplas possibilidades de construção de sentido presentes ou ausentes em cada texto. Não pretendemos, de fato, defender aqui a existência de transparência absoluta de sentido na linguagem, nem acreditamos na possibilidade de construção de sentidos estáticos e definidos, à maneira das "idéias fixas" de Platão. Pelo contrário, menos que a expressão de um ato de suprema liberdade, mapa decalcado de uma psique pessoal, o estilo é, em sentido inverso, uma conseqüência inevitável, uma "necessidade estrutural" decorrente da "multiplicidade de recursos disponíveis", e da complexidade do sistema lingüístico e semiológico em que se inscreve o sujeito da enunciação (POSSENTI, 1992, p. 15-16). Essas escolhas seguem esquemas, conscientes ou não, mais ou menos definidos, de acordo com o autor, e podem ser compreendidas como o exercício de táticas pessoais diante de estratégias discursivas socialmente dadas. 
Quando falamos de "táticas pessoais" estamos falando, naturalmente, de um "como". A propósito, Possenti enfatiza que o que caracteriza um texto autoral é antes um "como" do que um "o quê" (2002, p. 106-107). Creio que pretendeu dizer com isso que um bom texto, um texto, digamos, "estiloso", não é aquele com o qual estamos de acordo, ou que julgamos "útil e benéfico". Entretanto, julgo importante acrescentar a isso a idéia de que toda tática tem de ser, em alguma medida, intencional. E é o próprio Possenti quem frisa a necessidade, para que um texto tenha autoria, de que "faça sentido" (2002, p. 110) - observação que, de alguma maneira, nos remete a um "o quê". Poderíamos então concluir nosso raciocínio dizendo que o estilo não está nem na forma (conceito que aqui introduzo por minha conta) nem no conteúdo do texto, mas, justamente, entre os dois, no modo como o sujeito da enunciação os articula. Nesse sentido, a autoria não é exatamente uma forma (embora seja, afinal, um "como") porque não é estática, mas repousa sobre o dinamismo de uma ação - uma ação de inscrição.

Portanto, a autoria se caracteriza pelo "dar voz ao outro", pelo "dar-lhe ouvidos" e pelo "estilo pessoal". Poderíamos agora acrescentar ao nosso tripé, uma quarta atitude característica, para fazer assim, do autor, um quadrúpede. Essa característica é a "tomada de posição" (POSSENTI, 2002, p. 117 e 119). É uma atitude que diz respeito ao sentido do texto e, portanto, de algum modo, ao seu estilo (ao utilizar a palavra "sentido", gostaria de sugerir, para meu leitor, algo como a figura de um vetor, um direcionamento; o "estilo", por sua vez, é uma maneira própria de construir sentidos, isto é, construir significados e, conjuntamente, tomar partido). Essa "tomada de posição" é o resultado de uma inscrição lingüística no interior de uma discursividade; sendo pessoal, ou pelo menos "singular", só chega a se efetivar no interior de um campo dinâmico e social. Ora, isso explica, afinal, a importância do "dar voz e ouvido aos outros". O caminho para uma identidade pessoal (e discursiva) passa, como não poderia deixar de ser, pela alteridade.

Assim, com base nos textos aqui analisados, sobretudo no de Sírio Possenti, chego a uma conclusão que formulo nesses termos: 
a autoria é uma atitude de inscrição lingüístico-discursiva, uma tomada de posição que articula uma discursividade pretérita com uma posterior audiência, de acordo com táticas pessoais ou esquemas de estilo singularizados.

\section{NOTAS}

${ }^{1}$ Publicado pela primeira vez em 1968.

${ }^{2}$ Publicado pela primeira vez com o título Qu'est-ce qu'um auteur?, no Bulletin de la Société Française de Philosophie, ano 63, n. 3, p. 73-104, jul./set., 1969. Tratase de uma comunicação apresentada à Société Française de Philosophie na tarde de 22 de fevereiro de 1969, seguida de um debate.

${ }^{3}$ Publicado pela primeira vez em fevereiro de 1983 sob o título L'écriture de soi.

4 "Seria tão falso procurar o autor no escritor real como no locutor fictício; a função autor efectua-se na própria cisão - nessa divisão e nessa distância", (FOUCAULT, 2000, p. 55).

${ }^{5}$ Vale a pena abrir um parêntese aqui e mencionar a importância que a problemática da unidade (ou da falta de unidade) do sujeito da enunciação discursiva (conforme o pensamento lingüístico do século XX) assume em face de velhas questões de autoria e atribuição, e, em particular, em face da questão homérica.

${ }^{6}$ V. p. 174 deste trabalho.

\section{REFERÊNCIAS BIBLIOGRÁFICAS}

BARTHES, Roland. A morte do autor. In: O rumor da lingua. Tradução de Mário Laranjeira. São Paulo: Brasiliense, 1988. p. 65-70.

FOUCAULT, Michel. O que é um autor?. In: O que é um autor?. 4. ed. Tradução de António Fernando Cascais e Eduardo Cordeiro. Alpiarça: Vega, 2000. p. 29-87.

A escrita de si. In: O que é um autor? 4. ed. Tradução de António Fernando Cascais e Eduardo Cordeiro. Alpiarça: Vega, 2000. p. 129-160.

POSSENTI, Sírio. Enunciação, Autoria e Estilo. Revista da Faeeba; Universidade do Estado da Bahia, Departamento de Educação; Campus I, Salvador, v. 15, p. 15-21, 1992.

Indícios de autoria. Perspectiva; Revista do Centro de Ciências da Educação, Florianópolis, v. 20, n. 1, p. 105-124, jan./jun. 2002. 